\title{
Effects of nitrogen limitation on growth and nitrite excretion rates of the dinoflagellate Prorocentrum minimum
}

\author{
Antoine Sciandra, Rachid Amara \\ Observatoire des Sciences de l'Univers, Station Zoologique URA CNRS 716, Université Paris VI/INSU/CNRS, BP 28, \\ F-06230 Villefranche-sur-Mer, France
}

\begin{abstract}
Continuous nitrate-limited cultures of the dinoflagellate Prorocentrum minimum were grown under saturating photon flux densities to study the effects of nitrate pulses on the time variations of nitrate uptake, nitrite excretion, and cell division rate. In the first experiment, 5 chemostats were stabilized at the same dilution rate and, after stopping of the renewal supplies, received successively 1 pulse of nitrate at $24 \mathrm{~h}$ intervals. In the second, nitrate pulses were added about every $12 \mathrm{~h}$ in 1 chemostat. In the third experiment, 4 chemostats stabilized at different growth rates received 1 pulse of nitrate. Nitrate uptake process showed decreasing initial rates and lower maximum rates in cultures subjected to longer starvation times. In all cases, the amount of nitrite excreted before reabsorption represented an important proportion of the initially supplied nitrate (up to $45 \%$ ). This suggested that for nitrogen-deprived cells of $P$. minimum reduction of nitrite by the nitrite reductase is the more limiting step in the nitrate assimilatory pathway. The proportion of pulsed nitrate which is excreted as nitrite increased for decreasing growth rates. For 1 and $2 \mathrm{~d}$ of nitrate deprivation, the ratio nitrite excretion rate/nitrate uptake rate integrated during each perturbation experiment increased, but decreased after longer times of starvation. This suggests that the processes of nitrate uptake and nitrite reduction are affected at different rates during nitrogen deprivation. The implications of nitrite excretion in $\mathrm{N}$-limited cells on the determination of new production are discussed
\end{abstract}

KEY WORDS: Prorocentrum minimum - Nitrite excretion · Assimilation - Nitrite pulses

\section{INTRODUCTION}

Among the different forms of dissolved inorganic nitrogen which are assimilated by phytoplankton (ammonia, nitrate and nitrite), nitrite has been the least investigated. Simultaneous measurements of nitrate and nitrite (Carlucci et al. 1970, Kiefer et al. 1976, Harrison \& Davis 1977, Laws \& Wong 1978, Serra et al. 1978a, b, Olson et al. 1980, Collos 1982, Martinez 1991) have shown that nitrite excretion is a phenomenon of importance for the following 2 reasons. Firstly, the proportion of absorbed nitrate which is excreted as nitrite can be important; secondly, nitrite excretion is an indication of the uncoupling which can exist between the transport and assimilation of nitrate.

Nitrite excretion is a phenomenon which, parallel to studies on bacteria, was evoked to explain the pro- longed presence of a nitrite peak frequently associated with the nitracline and with the chlorophyll maximum found in certain oceanic regions: north and south of the equator in the Pacific (Hattori \& Wada 1971, Wada \& Hattori 1971) and on the North Atlantic coast (Vaccaro \& Ryther 1960). A simple box model was adapted and calibrated experimentally by Kiefer et al. (1976) for a central North Pacific region. Their results suggested that nitrate reduction by phytoplankton was sufficient to explain the peak of nitrite associated with the chlorophyll maximum. Generally, there are several conditions which are necessary for the establishment of a nitrite peak; sufficient algal biomass, a reduced illumination found below the compensation depth, and a substantial nitrate supply.

The nitrate and nitrite reductases involved in the conversions nitrate $\rightarrow$ nitrite and nitrite $\rightarrow$ ammonia 
have been well characterized in phytoplankton (Grant 1970 , Syrett 1981) but their regulation is not well known. If the excreted nitrite originates directly from absorbed nitrate, then the rate of nitrate reductase activity is greater than that of nitrite reductase. This means that nitrite reduction is the most limiting factor in the transport and reduction processes.

The first steps in the assimilation of nitrate involve reductive enzymatic reactions. In photosynthetic organisms, all ATP and reducing power ultimately come from photosynthesis. This can occur directly through the photosynthetic phosphorylation of ADP and reduced ferredoxin or indirectly through the respiration of previously fixed carbon compounds. Turpin (1991) has clearly presented the complex relations between photosynthetic production of carbon skeletons and reductants and their employment in the assimilation of inorganic nitrogen. Since photosynthesis and inorganic nitrogen absorption are closely coupled (Grant 1968, Grant \& Turner 1969, Turpin et al. 1988, Smith et al. 1992), it is difficult to explain the regulations imposed upon assimilation when growth is nitrogen limited. Under stable conditions, photosynthetic activity is defined by the degree of nitrogen limitation (Li \& Goldman 1981), but it is not clearly known how the availability of nitrogen affects photosynthesis.

We looked for the relationships existing between nitrite excretion and nitrogen limitation under constant and saturating light conditions for the dinoflagellate Prorocentrum minimum. These experiments are based on those reported in an earlier study where it was found that the uncoupling between the inorganic nitrogen uptake rate and the growth rate increased when the nitrogen deprivation was prolonged (Sciandra 1991). Since the sum of nitrate and nitrite concentrations was dosed, it was impossible to judge whether only the uptake was affected or whether assimilation was also involved. By simultaneously monitoring prolonged and continuous time series of nitrate uptake and nitrite excretion during the present study, it has been possible to follow the temporal effects of nitrogen deprivation on the uptake and assimilation processes, and to discriminate their respective importance from a dynamic point of view.

\section{MATERIALS AND METHODS}

The chemostats were cylindrical, double-walled glass containers with a capacity of $1.8 \mathrm{l}$. In all experiments the temperature was controlled by a thermostat set at $18^{\circ} \mathrm{C}$. Reversible magnetic stirrers were used to ensure homogeneous cultures $(80 \mathrm{rpm}$ and reversals every minute). Aeration was provided via filtration through activated charcoal and a Whatman filter $(0.1 \mu \mathrm{m})$. Continuous illumination was provided by 2 mercury lamps, and the intensity was measured by a probe (Biospherical Instrument, Inc., model QSL100) placed at the center of the containers. A Gilson peristaltic pump supplied the cultures with medium. Volume accuracy was controlled with a debit meter (ColeParmer Instruments). The nutritive medium was prepared using seawater obtained at $600 \mathrm{~m}$ depth and 3 miles from the Station Zoologique. The seawater was stored in the dark at $15^{\circ} \mathrm{C}$ until neither nitrite nor nitrate residues were detectable using a Technicon Analyser II (Tréguer \& Le Corre 1975). Before use, the seawater was filtered through Whatman $G F / F$, and autoclaved at $105^{\circ} \mathrm{C}$ for $30 \mathrm{~min}$. After cooling to room temperature, the seawater was enriched with $f / 4$ medium (Guillard \& Ryther 1962) which had been sterilized and nitrate- and phosphate-depleted. Final nitrate concentration was adjusted to $45 \mu \mathrm{g}$-at. $\mathrm{N}-\mathrm{NO}_{3}$ $\pm 3 \% \mathrm{l}^{-1}$. Phosphate was added to obtain a final N:P ratio of 14 . The supply medium was replaced every $4 \mathrm{~d}$. Although precautions were employed to ensure sterile conditions, the cultures were not axenic due to inherent problems with long-term culturing. Bacterial growth was, however, checked using DAPI, and found to be negligible.

The culture system used (Malara \& Sciandra 1991) permits the automatic sampling of nitrate and nitrite. Samples were also analyzed for the presence of ammonia, but results were negative. A HIAC particle counter (Pacific Scientific) was part of the culture system and established a spectrum of particles distributed into 12 size classes. Cell number and volume were calculated from the means of 3 consecutive measurements, and the maximum variation was $2 \%$. Measurements were taken every $8 \mathrm{~h}$ during all of the experiments.

Expt A. Five chemostats (Cultures A1 to A5) were aliquoted with 1.4 l of Prorocentrum minimum (Culture Collection UTEX. Austin, TX, USA) containing $2.3 \times$ $10^{7}$ cells $l^{-1}$ in an exponential growth phase. The photon flux density (PFD) varied from 235 to $250 \mu \mathrm{mol} \mathrm{m} \mathrm{m}^{-2}$ $\mathrm{s}^{-1}$ in the different experiments. With the introduction of additional medium to each chemostat, the maximal volume of $1.8 \mathrm{l}$ was attained and the dilution rate became $0.12 \mathrm{~d}^{-1}$. When equilibrium was established in the 5 chemostats, supply medium renewal was stopped $\left(t_{0}\right)$. A pulse of $9 \mu \mathrm{g}$-at. $\mathrm{N}-\mathrm{NO}_{3} \mathrm{l}^{-1}$ was then injected successively to the 5 cultures at ca $24 \mathrm{~h}$ intervals. The first sampling for nitrate and nitrite measurements was made 1 min after the pulse to allow for efficient mixing.

Expt B. A chemostat culture was stabilized at a growth rate of $0.052 \mathrm{~d}^{-1}$. PFD was $190 \mu \mathrm{mol} \mathrm{m} \mathrm{m}^{-2} \mathrm{~s}^{-1}$, and temperature was $18^{\circ} \mathrm{C}$. At $t_{0}$, the renewal supply medium was replaced with the same medium but lack- 
ing nitrate. Pulsing with nitrate then took place every $12 \mathrm{~h}$. The mean concentration of pulsed nitrate was equivalent to that supplied in continuous culturing.

Expt C. Lighting conditions were as in Expt B. Four chemostats (Cultures C1 to C4) were supplied with renewal medium at different dilution rates. When equilibrium was reached in each chemostat (i.e. $\mu=$ $0.05,0.13,0.18$ or $0.29 \mathrm{~d}^{-1}$ ), 1 nitrate pulse was delivered to each culture.

\section{RESULTS}

\section{Expt A}

After Day 21, algal densities varied by only $15 \%$ among cultures. On Day 22, biomass was stable and equilibrium was attained with growth being limited by the nitrogen supply $\left(\mu=0.12 \mathrm{~d}^{-1}\right)$. At this time $\left(t_{0}\right)$, the medium supply was stopped, and Cultures A1 to A5 were successively supplied with a nitrate pulse at $1 \mathrm{~d}$ intervals. Fig. 1 shows that the cell volume varied within a small range $(5 \%)$. Consequently, cell number can be used to estimate the population biomass and to calculate the growth rate from:

$$
\mu=\frac{\ln \left(n_{2}\right)-\ln \left(n_{1}\right)}{t_{2}-t_{1}}+d
$$

where $n_{1}$ and $n_{2}=$ algal density at time $t_{1}$ and $t_{2}$, respectively, and $d=$ dilution rate. In all cases, algal density increased when dilution was arrested (Fig. 2). The growth rate became negative in Cultures A2 to A5 within $2 \mathrm{~d}$ after $t_{0}$. In Culture $\mathrm{A} 1$, the growth rate remained positive due to the nitrate pulse at $t_{0}$. In all cultures, the nitrate pulses induced a positive growth rate after varying lengths of time. In Culture A1, the growth rate was even superior to that obtained during continuous culturing conditions. The essential difference between the experiments was due to the increase in lapsed time between the nitrate pulse and the growth rate maximum, which occurred in Cultures A1 through A5.

Fig. 2 shows the uncoupling between nitrate consumption and cell division. In Cultures A2 to A5, algal density did not increase until the pulsed nitrogen was completely consumed. The nitrate uptake was accompanied by nitrite excretion, which amounted to as much as $35 \%$ of the injected nitrate. A reabsorption of nitrite occurs when the concentration of nitrate drops below $1 \mu \mathrm{g}$-at. $\mathrm{N} \mathrm{I}^{-1}$. The rates of absorption and excretion were not the same in the chemostats (Fig. 3) but a common characteristic was noted in all; i.e. initial rates and maxima recorded during each pulse diminished in Cultures A1 to A5. For Cultures $A 3$ to $A 5$, the maximum rates measured for each per-

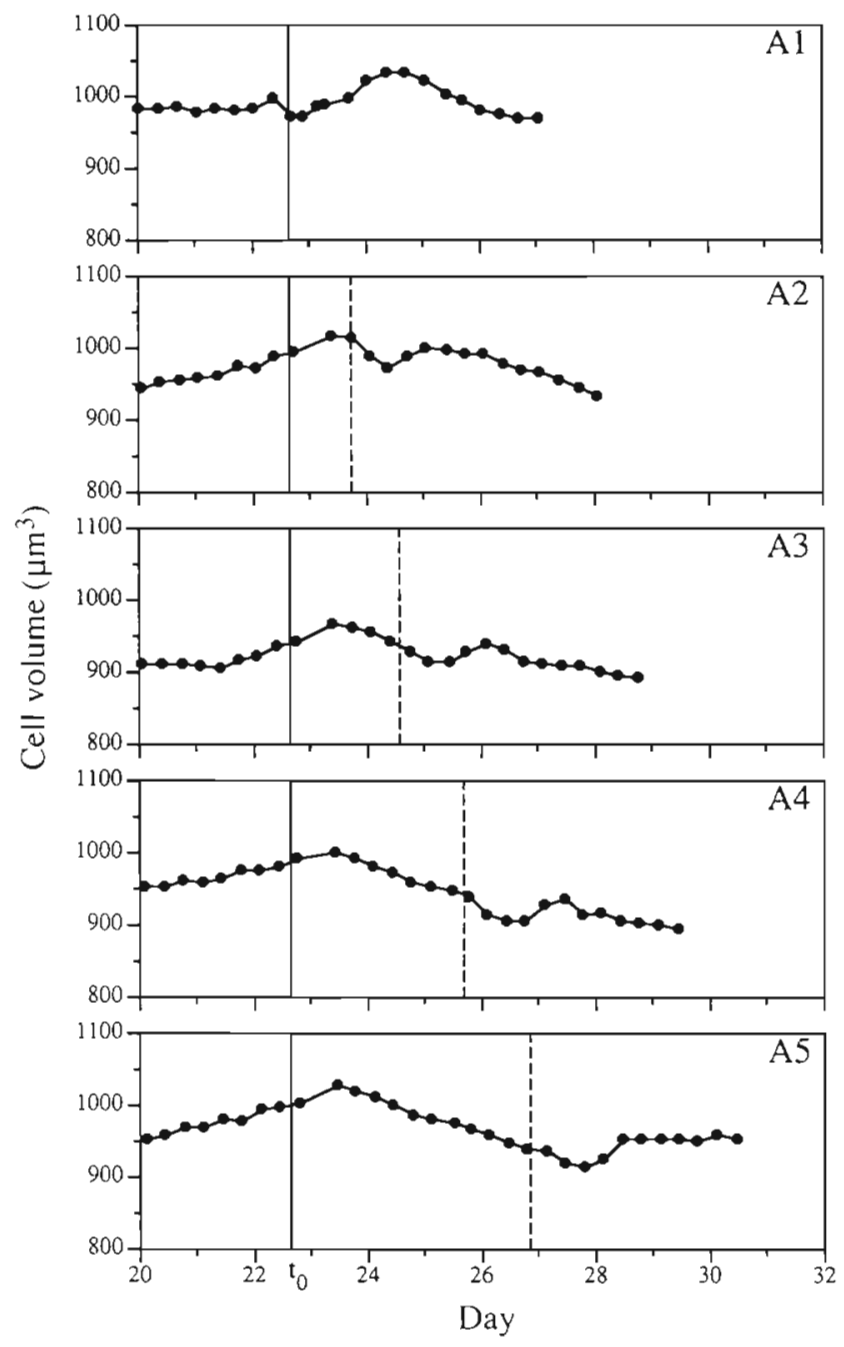

Fig. 1. Prorocentrum minimum. Expt A. Cell volume over time as affected by cessation of supply medium renewal ( $t_{0}$ : vertical solid line) and after nitrate pulses (vertical dashed line). In A1, cessation and nitrate pulse took place simultaneously

turbation were less than $2 / 3$ the maximum rates found in Culture A1. In Culture A1 $\left(\mu=0.12 \mathrm{~d}^{-1}\right)$, the maximum nitrate uptake rate was $0.41 \times 10^{-7} \mu \mathrm{g}$-at. $\mathrm{N}$ cell $^{-1} \mathrm{~h}^{-1}$ which is the same order of magnitude reported earlier for nitrate and nitrite absorption $(0.40 \times$ $10^{-7} \mu \mathrm{g}$-at. $\mathrm{N}$ cell ${ }^{-1} \mathrm{~h}^{-1}$ ) with a growth rate of $0.17 \mathrm{~d}^{-1}$ (Sciandra 1991). One also sees in Fig. 3 a symmetry in absorption and excretion for all cultures; high initial absorption rates correspond to high initial nitrite excretion rates and vice versa. Finally, the maxima of nitrite excretion and nitrate absorption occur at the same time. The series of data obtained from Culture A3, which are most complete and show the least amount of background noise, illustrates in detail the non-linearity of the processes. The rates of excretion and absorption are low at the beginning of 


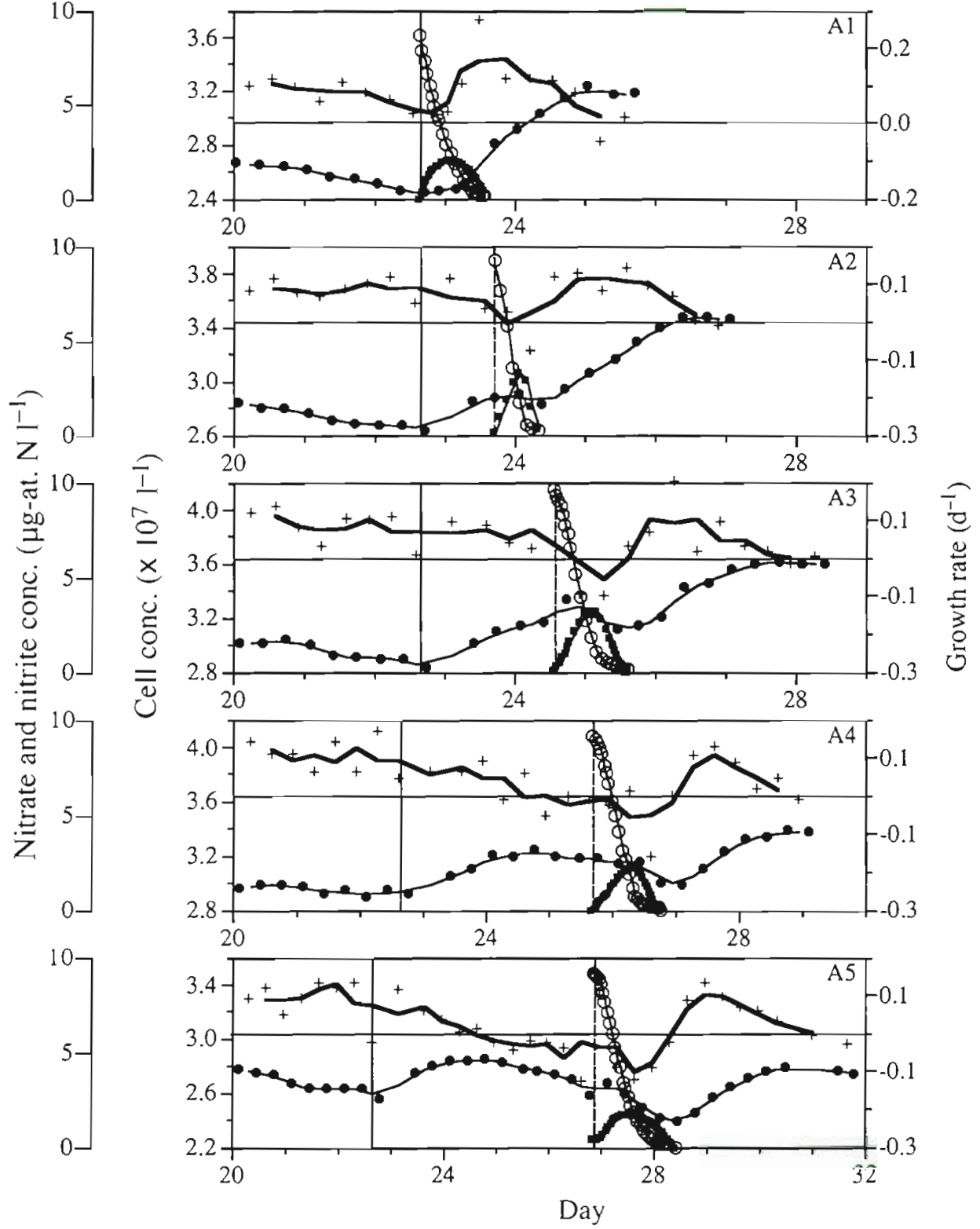

Fig. 2. Prorocentrum minimum. Expt A. Details of cell concentrations (O), growth rates (+), nitrate $(O)$ and nitrite (ם) concentrations after the cessation of supply medium (vertical solid line), and after nitrate pulses (vertical dashed line). Time changes of cell concentrations and growth rates are respectively smoothed by 2nd (thin lines) and 3rd order (thick lines) moving averages the perturbation. In the first phase, an induction phase greater than $5 \mathrm{~h}$ was necessary before the rates attained their maximum. In the second phase, the decline in nitrate absorption was concomitant to that of nitrite excretion. In the third phase, nitrite reabsorption became important, whereas nitrate uptake was maintained at a low level.

\section{Expt B}

Fig. 4 shows nitrite excretion and nitrate absorption in a continuous culture supplied with nitrate pulses at short intervals. Up to the 6th pulse, the decrease in algal density was the consequence of an increasing dilution rate; the renewal rate of the culture did not compensate the sampling used for nitrate, nitrite, and algal density measurements. The chemostat volume decreased from 1.8 to $1.5 \mathrm{I}$ between $t_{0}$ and $t=3.4 \mathrm{~d}$, when the medium renewal was discontinued. As in Expt $A_{1}$ an important proportion of injected nitrate was transformed to nitrite during the first 2 pulses. As of the 3rd pulse, the nitrate continued to be absorbed, but less rapidly, while the net nitrite excretion approached zero since the external concentration ceased to change after Day 2 . 


\section{Expt C}

The evolution of nitrate and nitrite after the pulses (data not shown) showed qualitatively the same 3 phases as in Expt A: (1) absorption of nitrate and nitrite excretion; (2) nitrate uptake reduced as reabsorption of nitrite commenced; and (3) simultaneous absorption of residual nitrate and nitrite. Fig. 5 shows that the proportion of the nitrate supplied which was excreted as nitrite was inversely related to the growth rate.

\section{DISCUSSION}

In Culture A1 (Fig. 3), the absorption rate continuously decreased, although the added pulse of nitrate was well above the halfsaturation constant. This was probably due to negative internal feedbacks. The products of reduction steps such as ammonia (Serra et al. 1978b, Tischner \& Lorenzen 1979, Dortch et al. 1991) and nitrite (Eppley \& Coatsworth 1968) can inhibit permeases, as well as the products arising from the assimilation of inorganic pools (Guerrero et al. 1981). Direct inhibition by internal nitrate, comparable to the reversible kinetics shown by ammonia (La Roche \& Harrison 1989), is not probable because of the rapid nitrite excretion observed, which proves that nitrate is rapidly reduced to nitrite. The results from Expt A1 can thus be interpreted by the following: cells which have been subjected to a small
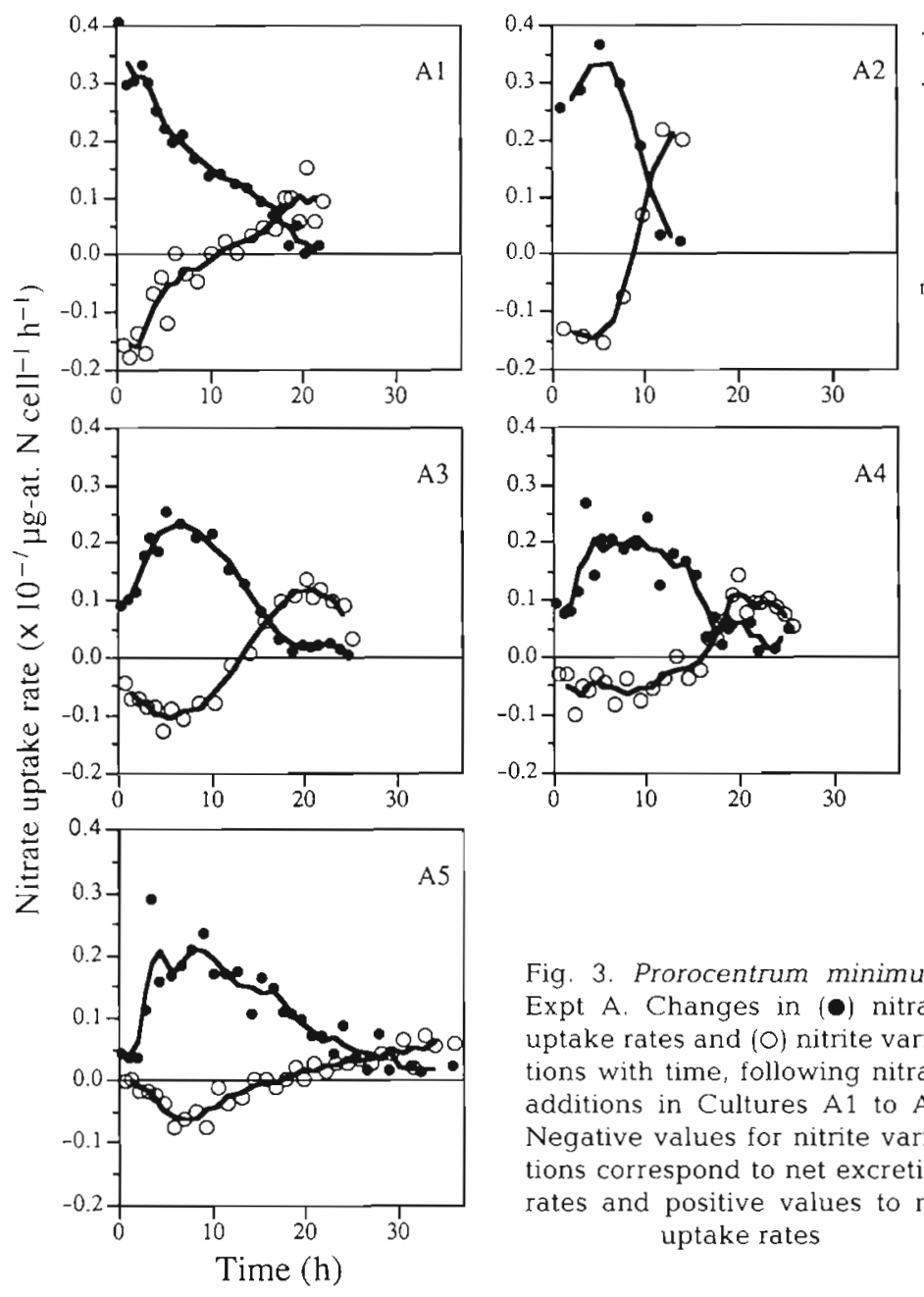

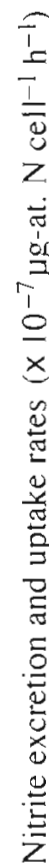

Fig. 3. Prorocentrum minimum Expt A. Changes in (1) nitrate uptake rates and (O) nitrite variations with time, following nitrate additions in Cultures A1 to A5. Negative values for nitrite variations correspond to net excretion rates and positive values to net uptake rates

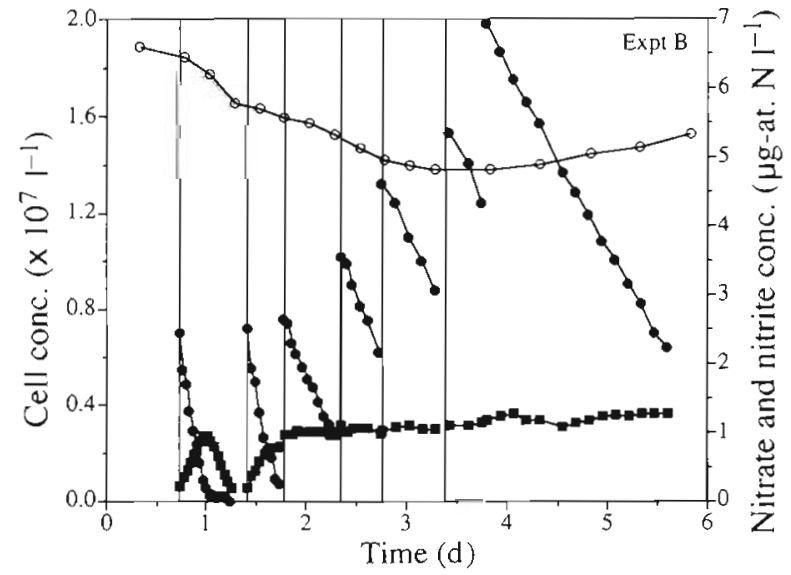

Fig. 4. Prorocentrum minimum. Expt B. Variations in concentration of $(O)$ cells, $(\bullet)$ nitrate and (ם) nitrite, following repeated additions of nitrate (vertical lines) into Culture $B$

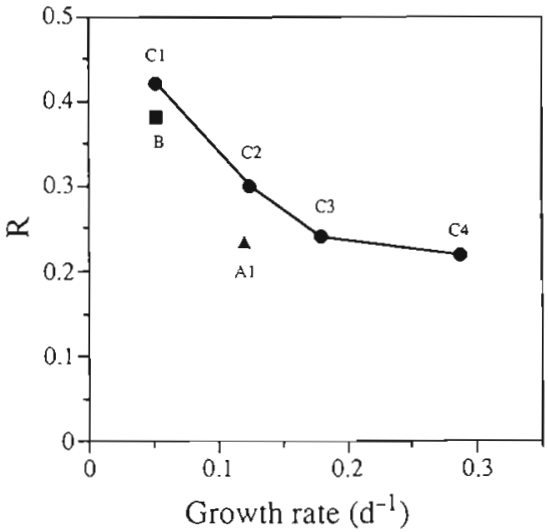

Fig. 5. Prorocentrum minimum. Expt $\mathrm{C}$. Ratio of the maximum nitrite and initial nitrate concentrations (R) compared with the growth rate measured for each perturbation experiment. $R$ values are also reported for the first perturbations of Expts $\mathrm{A}$ and $\mathrm{B}$ for which the steady-state growth rates were equal to the dilution rates 

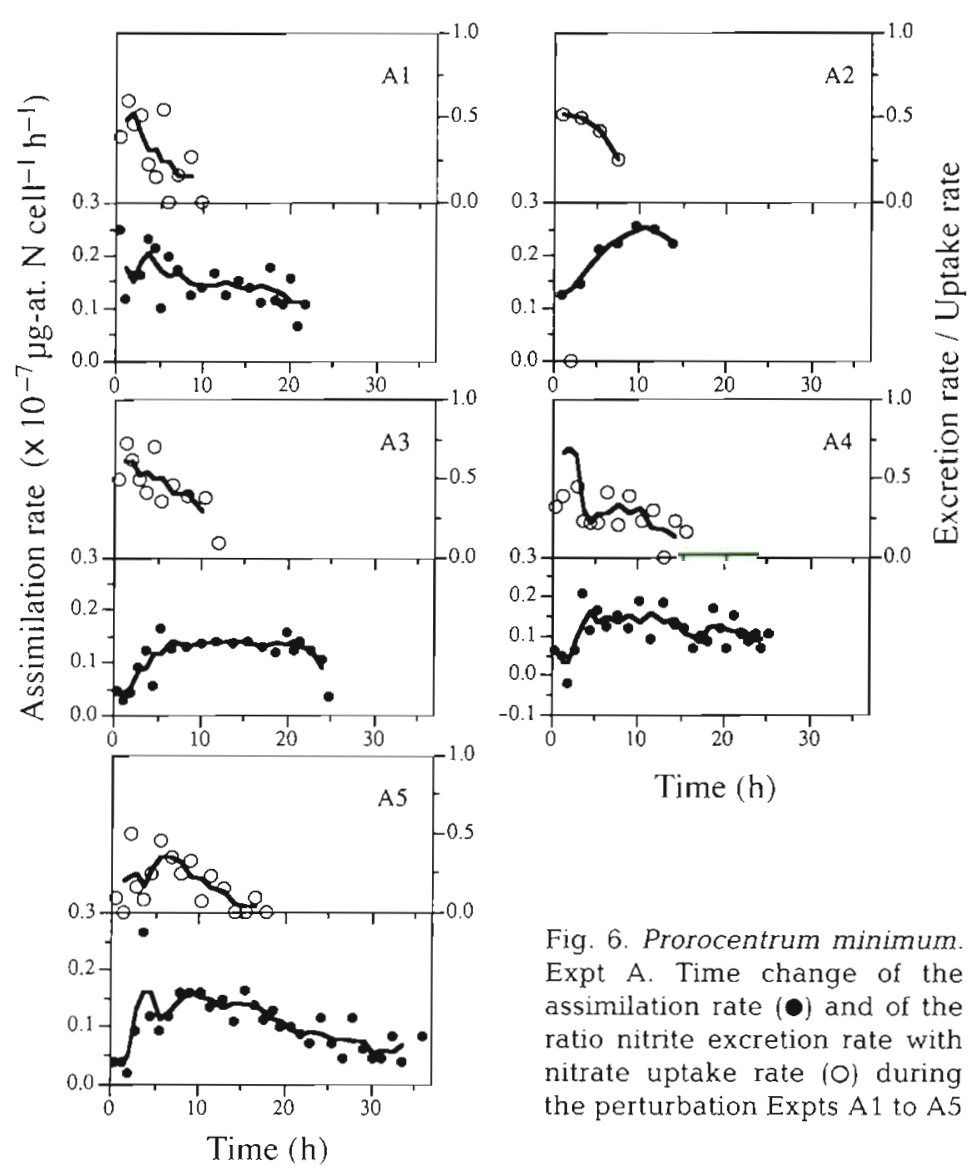

Fig. 6. Prorocentrum minimum. Expt A. Time change of the assimilation rate $(\bullet)$ and of the ratio nitrite excretion rate with nitrate uptake rate $(0)$ during the perturbation Expts A 1 to A.5
Fig. 3, the excreted nitrite derives from the absorbed nitrate. The nitrite reduction step can thus be more limiting than uptake and reduction of nitrate, contrary to conclusions advanced for other species. The release of nitrite by phytoplankton has been observed experimentally for diatoms and flagellates, and for natural communities (see references cited in the 'Introduction'). Our data conform to what is typically observed; (1) nitrite excretion occurs when an excess amount of nitrate is provided to nitrate-limited cells; (2) nitrite accumulates in the milieu during nitrate absorption, and (3) as the nitrate concentration decreases to critical levels ranging from 0.5 to $3 \mu \mathrm{g}$-at. $\mathrm{l}^{-1}$, the uptake of nitrate slows down and the nitrite is reabsorbed. At the end of the incubation, nitrate and nitrite are taken up simultaneously until exhaustion.

In view of the literature, the rate of nitrite excretion shows considerable amplitude differences among species. It is not easy to state if these variations are species specific; firstly the nitrite dynamics by phytoplankton have not received extensive analysis and the existing studies have mostly been carried out with diatoms. Secondly, strong differences are observed for the same species. This intraspecific variability can be explained by

degree of nitrate limitation retain a substantial capacity to transport nitrate compared with their ability to assimilate it. Transport inhibition occurs through progressive accumulation of factors issuing from reduction processes. The rest of Fig. 3 demonstrates that prolonged nitrogen deprivation has a negative effect on nitrate uptake. Relationships have been established between the degree of deficiency and nitrate uptake (Dortch et al. 1982, Parslow et al. 1984, Cochlan \& Harrison 1991), but the regulations are complex and not well defined. The permeases might be degraded during the periods of deficiency and resynthesized de novo upon reintroduction of nitrate in the medium (Neyra \& Hageman 1975). It follows that the induction time required for de novo synthesis of permease depends on the degree of nitrate deficiency and could explain why both initial transport of nitrate and excretion of nitrite are increasingly affected by longer times of starvation.

The term 'nitrite excretion' corresponds to an outward passive or active flux superior to an inward flux, which can be simultaneous. Nitrite excretion in Prorocentrum minimum is a non-negligible process which depends upon the degree of nitrogen limitation (Fig. 5). In view of the kinetic symmetries shown in assuming that nitrite dynamic results from the combination of the uptake and reduction processes which are each regulated by the interdependent $\mathrm{C}$ and $\mathrm{N}$ metabolisms. Under light-limited conditions, the degree of nitrogen deprivation influences the release of nitrite. Laws \& Wong (1978) argued that the release of nitrite by phytoplankton during nitrate spike experiments occurs commonly when cells have not been previously conditioned to assimilate nitrate rapidly. Nitrite excretion is a transient response resulting from a sudden increase in uptake rate. Serra et al. (1978a) equally observed that when $\mathrm{N}$-deficient cells of Skeletonema costatum were preincubated for $4 \mathrm{~h}$ with nitrate, the release of nitrite was less (although the nitrate uptake was higher) than without preincubation. Highest excretion rates in cells of $S$. costatum have been measured after $36 \mathrm{~h}$ of $\mathrm{N}$ starvation (Martinez 1991); shorter and longer periods of starvation lead to less important release of nitrite. Fig. 4 shows that when $N$ limited cells have been preconditioned by 2 daily additions of nitrate, the release of nitrite does not occur if further additions are performed. This can be explained by the fact that the assimilation rate is enhanced when the cells are conditioned by previous nitrate additions. On the other hand, Fig. 4 could support the hypothesis 
that the accumulation of external nitrite inhibits further nitrite excretion as suggested by Kiefer et al. (1976). Our data shows that an accumulation of external nitrite is accompanied by an important decrease in nitrate absorption after the 3rd pulse. As an explanation, one could consider a competition of nitrate and nitrite for the same enzymatic sites (Eppley \& Coatsworth 1968, Bilbao et al. 1981, Olson et al. 1980). However, one can equally suggest the aforementioned, that internal nitrite accumulates and subsequently inhibits the nitrate permeases. One cannot exclude the possibility that both mechanisms coexist.

The assimilation rate, calculated as the difference between nitrate uptake and net nitrite excretion rates (Fig. 6), attains a maximum identical value in Cultures A3, A4 \& A5. This suggests that $2 \mathrm{~d}$ of nitrogen deprivation is sufficient to significantly reduce the level of nitrite reductase activity in $\mathrm{N}$-limited cells, and that more prolonged deprivation does not lead to increased reduction. Fig. 6 shows that the net release of nitrite decreases more rapidly than the nitrate uptake, suggesting a readjustment of the nitrite reductase activity due to nitrate addition. Fig. 7 shows the combined data from Expt A. The change in the ratio of these processes integrated for each experiment is not uniform during the increasing periods of deprivation in Cultures A1 to A5. This suggests that transport and reduction limit the assimilation at different times after the onset of $\mathrm{N}$ starvation. When the ratio increased, the nitrite reduction became more limiting than nitrate uptake, and vice versa.

The nitrite maximum, often observed just below the nitracline where photosynthesis can be limited, has been interpreted principally as a cellular incapacity to reduce nitrite to ammonia due to a deficit of photo-

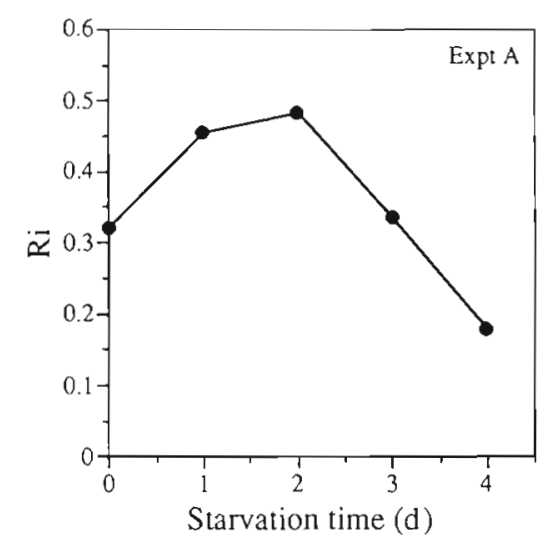

Fig. 7. Prorocentrum minimum. Expt A. Effect of nitrogen deprivation on $\mathrm{Ri}$, calculated as the integral of the ratio excretion/uptake rates shown in Fig. 6 during each perturbation experiment generated reductants (Tischner \& Lorenzen 1979). Low levels of irradiance have usually been shown as a major condition for nitrite excretion. Using Skeletonema costatum, Vaccaro \& Ryther (1960) showed that the highest concentrations of nitrite were produced in the dark and that the amount decreased progressively as the PFD increased. For cultures of the same species starved for $36 \mathrm{~h}$ and grown at low PFD $\left(50 \mu \mathrm{mol} \mathrm{m} \mathrm{m}^{-2} \mathrm{~s}^{-1}\right)$, Martinez (1991) found that $35 \%$ of the nitrate consumed was excreted as nitrite. For N-starved cultures of Monochrysis lutheri, Dunaliella tertiolecta and Thalassiosira allenii, Laws \& Wong (1978) observed a more rapid nitrite release during the night than the day. Collos (1982) reported the same tendency with nitrate-growing cells of Phaeodactylum tricornutum.

As internal carbon and nitrogen were not measured in our experiments, we have no real index of growth limitation, even if it is reasonable to consider that the degree of nitrogen limitation increased with the time of $\mathrm{N}$ starvation. Nevertheless, since cell carbon and cell volume are generally well correlated (Thompson et al. 1991), Fig. 1 can be considered as appropriately representing the time variation of cell carbon in Expt A. In all cultures except Culture A1, the cell volume decreased $24 \mathrm{~h}$ after the beginning of the starvation period. Nitrate pulses led to a small, transient but significant increase of the cell volume approximately $24 \mathrm{~h}$ later, which probably corresponded to a parallel increase in cell carbon.

Our data show that nitrite excretion may reach high rates although the irradiance level is potentially saturating for photosynthesis (Harding et al. 1987). Due to a reciprocal coupling of nitrogen assimilation and carbon incorporation pathways (Turpin 1991), any deficiency in one or the other pathway induces a readjustment of the other. It is probable that nitrogen starvation placed the cells in a physiological state were they could not actually use the light. Either or both the light or dark systems are likely to be operating less efficiently after $\mathrm{N}$ deprivation (Falkowski et al. 1989). When inorganic nitrogen was resupplied after starvation, the cells readjusted not only their nitrogen pathways for de novo enzyme synthesis, but also their photosynthetic apparatus to provide necessary reductants. These results underline the difficulty of defining a real index of growth limitation. Times of nitrogen deprivation used in this study cannot be used in comparing works by others because the past history of carbon metabolism modulates the effects of deprivation. Since carbon and nitrogen metabolisms are not separable, the definition of 1 limiting factor (the factor that enhances growth if it is supplied in the medium) is ambiguous. When Prorocentrum minimum is resupplied with nitrate after nitrogen starvation, the assimilation and consequently the growth is limited 
by factors provided by the carbon pathways, and during a transient phase the carbon becomes the limiting factor.

A major consequence of the release of external nitrite by $\mathrm{N}$-limited cells may lead to biased estimations of the new production and the $f$ ratio (Dugdale \& Goering 1967). In stratified situations, nitrate arising from deep waters is principally absorbed at depths where growth is light and/or nitrate limited. At the onset of the incubations on the deck, cells are generally submitted to an increase of nutrients large enough to obtain accurate kinetics, and are then exposed to nitrite excretion. When using the ${ }^{15} \mathrm{~N}$ isotope technique, or if nitrate is not monitored separately from nitrite with a colorimetric method, the true transport rate of nitrate may be underestimated during the time where nitrite is excreted, and overestimated when $\mathrm{NO}_{2}$ is reabsorbed (Collos 1982). The bias may be important because the amount of excreted nitrite may reach a great proportion of the added nitrate (about $50 \%$ in our experiments), and also because the 12 to $24 \mathrm{~h}$ traditionally used for deck incubations are of the same magnitude required for the cells to recover a steady state. Our results show that the nitrite excretion is related to the degree of nitrogen limitation. Estimations of new production may be more biased in well-stratified regions than in young upwelling areas.

Another implication of this work is to emphasize the difficulty in providing a theoretical framework of phytoplankton dynamics in a changing nutrient environment. A deterministic approach utilized in many types of models has resulted in a phenomenological representation of the processes. Unfortunately, the level of complexity of the models employed does not take the dynamics of interacting cellular components fully into account, due to modeling constraints. This would be less of a problem if the qualitative aspect of the dynamics did not play such an important, if indeed not more important, role compared to the quantitative exchanges of material. The aforementioned mathematical insufficiency is paradoxical, because biological models are now coupled with physical models which allow one to take the diverse nitrate supplies inta account. The paradox lies essentially in the theoretical representation of biological processes which still employ equations (for example Michaelis-Menten relationship) which describe experimental processes under stationary conditions. These equations do not adequately describe situations where the external variability stimulates adaptive processes of the species. Another bias, inherent to a phenomenological concept of modeling, is equally introduced when independent formulations are given to model nitrogen assimilation and carbon fixation separately, which, in reality, are intrinsically associated.
Acknowledgements. We thank Gilbert Malara for his technical assistance and Patrick Chang for the English. We also thank the anonymous reviewers for their valuable comments. This re search was supported by funds from the Programme National Environnement 'Modèles, Méthodes et Théories' and by CNRS (Département TOAE; UA716: Ecologie du Plancton Marin).

\section{LITERATURE CITED}

Bilbao, M., Gabas, J. M., Serra, J. L. (1981). Inhibition of nitrite uptake in the diatom Phaeodactylum tricornutum by nitrate, ammonium ions and some L-amino acids. Biochem. Soc. Trans. 9: 476-477

Carlucci, A. F., Hartwing, E. O., Bowes, P. M. (1970). Biological production of nitrite in sea water. Mar. Biol. 7 : $161-166$

Cochlan, W. P., Harrison, P. J. (1991). Uptake of nitrate, ammonium, and urea by nitrogen-starved cultures of Micromonas pusilla (Prasinophyceae): transient responses. J. Phycol. 27: 673--679

Collos, Y. (1982). Transient situations in nitrate assimilation by marine diatoms. II. Changes in nitrate and nitrite following a nitrate perturbation. Limnol. Oceanogr. 27: $528-535$

Dortch, Q., Clayton, J. R., Thoresen, S. S., Bressler, S. L., Ahmed, S. I. (1982). Response of marine phytoplankton to nitrogen deficiency: decreased nitrate uptake vs. enhanced ammonium uptake. Mar. Biol. 70: 13-19

Dortch, Q., Thompson, P. A., Harrison, P. J. (1991). Short-term interaction between nitrate and ammonium uptake in Thalassiosira pseudonana: effect of preconditioning nitrogen source and growth rate. Mar. Biol. 110: 183-193

Dugdale, R. C., Goering, J. J (1967). Uptake of new and regenerated forms of nitrogen in primary productivity. Limnol. Oceanogr. 12: 196-206

Eppley, R. W., Coatsworth, J. L. (1968). Uptake of nitrate and nitrite in Ditylum brightwelli, kinetics and mechanisms. J. Phycol. 4: 151-156

Falkowski, P. G., Sukenik, A., Herzig, R. (1989). Nitrogen limitation in Isochrysis galbana (Haptophyceae). II. Relative abundance of chloroplast proteins. J. Phycol. 25: 471-478

Grant, B. R. (1968). The effect of carbon dioxide concentration and buffer system on nitrate and nitrite assimilation by Dunaliella tertiolecta. J. gen. Microbiol. 54: 327-336

Grant, B. R. (1970). Nitrate reductase in Dunaliella tertiolecta: isolation and properties. Plant Cell Physiol. 11. 55-64

Grant, B. R., Turner, I. M. (1969). Light-stimulated nitrate and nitrite assimilation in several species of algae. Comp. Biochem. Physiol. 29: 995-1004

Guerrero, M. G., Vega, J. M. Losada, M. (1981), The assimilatory nitrate-reducing system and its regulation. A. Rev. Plant Physiol. 32: 169-204

Guillard, R. R., Ryther, J. H. (1962). Studies of marine planktonic diatoms. 1. Cyclotella nana Hustedt and Detonula confervacea (Cleve.) Gran. Can. J. Microbiol. 8: 229-239

Harding, L. W., Fisher, T. R., Tyler, M. A. (1987). Photosynthetic physiology of Prorocentrum mariae-lebouriae (Dinophyceae) during its subpycnocline transport in Chesapeake Bay. J. Phycol. 24: 77-89

Harrison, P. J., Davis, C. O. (1977). Use of the perturbation technique to measure nutrient uptake rates of natural phytoplankton populations. Deep Sea Res. 24: 247-255

Hattori, A., Wada, E. (1971). Nitrite reduction and its regulating processes in the equatorial Pacific Ocean. Deep Sea Res. 18: $557-568$ 
Kiefer, D. A., Olson, J. R., Holm-Hansen, O. (1976). Another look at the nitrite and chlorophyll maxima in the central North Pacific. Deep Sea Res. 23: 1199-1208

La Roche, J., Harrison, W. G. (1989). Reversible kinetic model for the short-term regulation of methylammonium uptake in two phytoplankton species Dunaliella tertiolecta (Chlorophyceae) and Phaeodactylum tricornutum (Bacillariophyceae). J. Phycol. 25: 36-48

Laws, E. W., Wong, D. C. L. (1978). Studies of carbon and nitrogen metabolism by three marine phytoplankton species in nitrate-limited continuous culture. J. Phycol. 14: $406-416$

Li, W. K. W., Goldman, J. C. (1981). Problems in estimating growth rates of marine phytoplankton from short term ${ }^{14} \mathrm{C}$ assays. Microbiol. Ecol. 7: 113-121

Malara, G., Sciandra, A. (1991). A multiparameter phytoplanktonic culture system driven by microcomputer. J. appl. Phycol. 3: 235-241

Martinez, R. (1991). Transient nitrate uptake and assimilation in Skeletonema costatum cultures subject to nitrate starvation under low irradiance. J. Plankton Res. 13: 499-512

Neyra, C. A., Hageman, R. H. (1975). Nitrate uptake and induction of nitrate reductase in excised corn roots. Plant Physiol. 56: 692-695

Olson, R. J., SooHoo, J. 3., Kiefer, D. A. (1980). Steady-state growth of the marine diatom Thalassiosira pseudonana. Uncoupled kinetics of nitrate uptake and nitrite production. Plant Physiol. 66: 383-389

Parslow, J. S., Harrison, P. J., Thompson, P. A. (1984). Saturated uptake kinetics: transient response of marine diatom Thalassiosira pseudonana to ammonium, silicate or phosphate starvation. Mar. Biol. 83: 51-59

Sciandra, A. (1991). Coupling and uncoupling between nitrate uptake and growth rate in Prorocentrum minimum (Dinophyceae) under different frequencies of pulsed nitrate supply. Mar. Ecol. Prog. Ser. 72: 261-269

This article was submitted to the editor
Serra, J. L., Llama, M. J., Cadenas, E. (1978a). Nitrate utilization by the diatom Skeletonema costatum. I. Kinetics of nitrate uptake. Plant Physiol. 62: $987-990$

Serra, J. L., Llama, M. J., Cadenas, E. (1978b). Nitrate utilization by the diatom Skeletonema costatum. II. Regulation of nitrate uptake. Plant Physiol. 62: 991-994

Smith, G. J., Zimmerman, R. C., Alberte, R. S. (1992). Molecular and physiological responses of diatoms to variable levels of irradiance and nitrogen availability: growth of Skeletonema costatum in simulated upwelling conditions. Limnol. Oceanogr. 37: 989-1007

Syrett, P. J. (1981). Nitrogen metabolism in microalgae. In Platt, T. (ed.) Physiological bases of phytoplankton ecology. Can. Bull. Fish. Aquat. Sci. 210: 182-210

Thompson, P. A., Harrison, P. J., Parslow, J. S. (1991). Influence of irradiance on cell volume and carbon quota for 10 species of marine phytoplankton. J. Phycol. 27: 351-360

Tischner, R., Lorenzen, H. (1979). Nitrate uptake and nitrate reduction in synchronous Chlorella. Planta 146: 287-292

Tréguer, P., Le Corre, P. (1975). Manuel d'analyse des sels nutritifs dans l'eau de mer. Laboratoire d'Océanologie et de Chimie, Université de Bretagne Occidentale, Brest, p. 110

Turpin, D. H. (1991). Effects of inorganic $\mathrm{N}$ availability on algal photosynthesis and carbon metabolism. J. Phycol. 27: $14-20$

Turpin, D. H., Elrifi, 1. R., Birk, D. G., Weger, H. G., Holmes J. J. (1988). Interactions between photosynthesis, respiration, and nitrogen assimilation in microalgae. Can. J. Bot 66: $2083-2097$

Vaccaro, R. F., Ryther, J. H. (1960). Marine phytoplankton and the distribution of nitrite in the sea. J. Cons. perm. int Explor. Mer 25: 260-271

Wada, E., Hattori, A. (1971). Nitrite metabolism in the euphotic zone of the Central Pacific Ocean. Limnol. Oceanogr. 16: 766-772

Manuscript first received: May 24, 1993

Revised version accepted: December 9, 1993 